\title{
ARTÍCULO
}

BIBLIOGRÁFICO

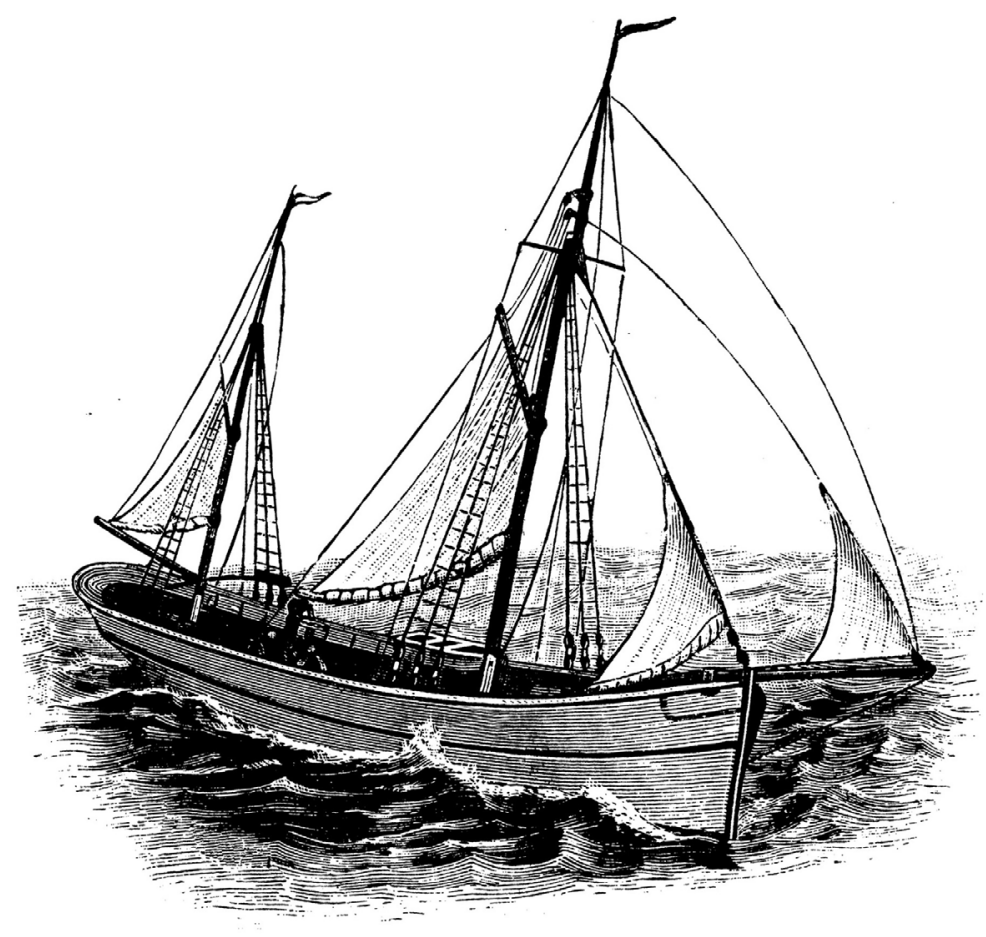



TRANS · núm. I7 · 2013

ARTICULO BIBLIOGRÁFICO · 205-210

\section{Una traducción baudelairiana de los Petits poèmes en prose}

\section{David Marín Hernández \\ Universidad de Málaga}

Más de un siglo después de su publicación, los Petits poèmes en prose de Charles Baudelaire siguen generando nuevas traducciones, síntoma de la buena salud de la que goza esta obra póstuma del poeta francés. Si uno de los criterios para incluir una obra entre los clásicos de la literatura universal es su capacidad de seguir suscitando nuevas interpretaciones con el transcurso del tiempo, no hay duda de que el poemario de Baudelaire merece figurar en la nómina de este selecto canon. Desde su aparición en 1869 , lectores de todo el mundo han ido interpretando ( $\mathrm{y}$ traduciendo) estos poemas en prosa una y otra vez; lecturas variadas que demuestran que Baudelaire sigue dialogando con las nuevas generaciones. Desde que Eusebio Heras los tradujera por vez primera en 1905, los Petits poèmes en prose han sido vertidos en español en dieciocho ocasiones ${ }^{\mathrm{I}}$. Bien es cierto que

I Cuento solo las traducciones de la totalidad de la obra, no las muchas versiones de poemas sueltos publicadas en prensa escrita o en antologías. Por razones obvias, también dejo fuera de este cómputo las ediciones que se han limitado a reproducir traducciones previas cambiando sin escrúpulos el nombre del traductor. no todas estas retraducciones suponen nuevas lecturas de la obra original. Un escritor clásico libre de derechos de autor y con cierto tirón comercial es una tentación difícil de resistir para aquellas editoriales dispuestas a prestigiar su catálogo con grandes nombres, de ahí que con frecuencia vean la luz nuevas traducciones de Baudelaire que nada añaden a las anteriores y que tienen la única función de lograr lo que Bourdieu llamaría una transferencia de «capital simbólico» (y no tan simbólico) entre el escritor francés y la empresa editora.

No es el caso de la última versión española de los Petits poèmes en prose, publicada en octubre de 2012 por el poeta y traductor alicantino Jesús Belotto bajo el llamativo título París/Spleen. Poemas en prosa. Se trata de una traducción que, ante los retos que plantea el texto francés, propone soluciones originales hasta ahora no exploradas en las versiones anteriores. La originalidad en sí misma no es garantía de satisfacción - las opciones por las que se decanta Belotto son, como todas, discutibles-, pero no hay duda de que en este caso sí estamos ante 
una nueva traducción que amplía la recepción de Baudelaire en España y la enriquece al hacerla más diversa. Veamos un primer ejemplo. E1 poema 47 («Mademoiselle Bistouri») permite ilustrar un clásico problema de traducción. En él aparece una expresión malsonante atenuada mediante puntos suspensivos: «Non ! non ! à moins que ce ne soit pour te couper la tête ! S... s... c... de s... m...!». Bajo esos puntos se adivina la blasfemia «Sacré Saint Cibore de Sainte Maquerelle». Los procedimientos por los que se habían decantado hasta ahora los traductores españoles ante esta muestra de recato han sido múltiples: algunos habían preferido mirar hacia otro lado y suprimir cualquier referencia a la blasfemia (como Enrique Díez-Canedo o José Antonio Millán Alba, en cuyas versiones no quedan restos de las expresiones francesas); otros habían optado por mantener tal cual las iniciales francesas con sus puntos suspensivos (Manuel Neila: «¡No, no! A menos que sea para cortarte la cabeza... ¡S... s... c... de... s... m...!»); en algunas traducciones se habían utilizado expresiones españolas equivalentes, suavizadas también por puntos (Enrique López Castellón: «Me c... en la p... que te p...!»); en otras versiones se podían leer adaptaciones más o menos malsonantes (Torres Monreal: «¡Por la hostia sagrada!»; Gil-Vilache: «¡Perra sucia! ¡Golfa!»; Pedro Gandía: «PPuñetero santo copón de santa alcahueta!»). En el estudio introductorio que precede su reciente traducción, Jesús Belotto explica que el recurso a estos puntos suspensivos no fue una decisión de Baudelaire (en los poemas manuscritos que se encontraron tras su muerte aparece la expresión de forma explícita), sino que fueron los editores Banville y Asselineau quienes, al publicar de forma póstuma el poemario, decidieron rebajar el tono de las blasfemias mediante los mencionados puntos. Partiendo de este dato, Belotto considera «ridículo» seguir manteniendo esta censura en el siglo XXI, pero se siente obligado a mantenerse fiel a la edición original de Banville y Asselineau; de ahí que, para conciliar estos dos principios tan baudelairianos (el sometimiento a la edición clásica, por un lado, y la búsqueda de la modernidad, por otro), haya traducido los puntos suspensivos por símbolos onomatopéyicos propios de los cómics. Consciente de la sorpresa que esta decisión causará en no pocos lectores, el traductor se justifica apelando al mismo espíritu transgresor que animó a Baudelaire en la escritura de sus poemas en prosa: «[...] si los poemas en prosa de Baudelaire atentaron desde sus primeras publicaciones contra las convenciones poéticas del momento y abrieron una vía a la confusión (fusión con) de géneros, no se puede sostener del mismo modo que hayamos atentado contra el espíritu de los Petis poèmes en prose a pesar de nuestro osado toque mortadelesco" (Belotto, 20I2: xxvi-xxvii).

Tanto el procedimiento de traducción que acaba de describirse como su justificación ilustran bien el rasgo quizás más sobresaliente de esta versión: la afinidad entre el traductor y el autor del texto original. Jesús Belotto quiere traducir a Baudelaire aplicando los mismos principios estéticos baudelairianos que subyacen en los poemas en prosa. La naturaleza maleable de este nuevo género literario (al que el poeta francés recurrió precisamente por su ductilidad formal) parece dar rienda suelta al traductor, que no duda en recurrir a instrumentos propios del tebeo para traducir a un autor consagrado. La desenvoltura con la que se mezclan en la traducción diversos registros lingüísticos se ampara en la misma libertad que se tomó Baudelaire para moldear a su gusto los poemas en prosa, que unas veces adoptaban la forma del microrrelato y otras se presentaban bajo una brevedad lírica de gran intensidad. 
Belotto parece haber hecho suya la máxima que predicaba Juan Ramón Jiménez: «Únicamente debe traducirse cuando lo que uno lee de otro le sea tan íntimo, tan propio a uno, que sintamos a un tiempo que es de uno y no lo es» (citado en Ruiz Casanova, 2000: 479). Estamos ante un nuevo ejemplo de que la "poética propia [es] el impulso de la retraducción» (Ruiz Noguera, 2007: I79). En efecto, no resulta difícil apreciar la influencia de Baudelaire en la propia obra poética de Jesús Belotto: en su poema en prosa «Os veo detrás del cristal de las vitrinas» ${ }^{2}$ (de Una luz de relámpagos) contemplamos a un transeúnte desorientado ante la diversidad de estímulos que le llegan de una gran urbe en permanente metamorfosis, personaje recurrente en la obra de Baudelaire.

Al margen de otros ecos esplínicos en los versos de Belotto, ${ }^{3}$ lo interesante de su traduc-

2 «En las vitrinas estáis: tacones de quince centímetros, vaqueros desgastados, camisetas transgresivas, relojes de acero, joyas y baratijas, zapatillas de ronaldo, piercings en el ombligo, somebody forgot his rayban sanglasses, estáis temporada otoño-invierno, cincuenta por ciento de descuento, estáis maniquíes calvos y bulímicos, máscaras venecianas con i-pods en las orejas, aves en la cazuela, peces en la pecera, estáis en stock en todas las vitrinas.

Yo paso y, desde fuera, me veo reflejado al otro lado.

$(\mathrm{O}$ acaso es mi reflejo el que mira

y yo estoy aquí dentro

con vosotros.)»

3 «Te mecerá en tus tardes solitarias/ el ritmo vaginal de los tranvías./ Una vez al año, te dará el visto bueno / tu dentista. Una vez al mes,/ lavarás tu coche de segunda mano./ Una vez por semana - tal vez / el sábado a las 23:30 -,/ le llenarás la boca de esperma a tu pareja / pensando en el escote vulgar de alguna alumna./Te sentirás vivo ocasionalmente,/ cuando te dé un nuevo latigazo el nervio ciático,/ te crecerán las venas a la hora / de sacar a cagar al perro y del suicidio // Y nada será grave. O /casi nada.» («Nada grave», Una luz de relámpagos). La descripción que Baudelaire nos hizo del moderno urbanita no solo sigue reapareciendo en la poesía contemporánea. La cinematografía más reciente nos ofrece también interesantes ejemplos que demuestran la actualidad de sus intuiciones. En la película Shame (2oII), de Steve McQueen, el personaje interpretado por Michael Fassbender es incapaz de liberar- ción, como se ha dicho, es que en el proceso de reescritura de los Petits poèmes en prose se ha sentido inspirado por el mismo impulso poético que informa la obra de Baudelaire. Estamos ante una «traducción poética» no porque el objeto traducido sea un poema, sino porque la actividad traductora en sí misma se ha considerado poética y como tal se ha practicado. Se diría que ante las decisiones de traducción que ha tenido que tomar durante este proceso creativo, Jesús Belotto se ha formulado siempre la misma pregunta: no tanto «¿qué ha querido decir Baudelaire con esto?» como "¿qué habría hecho Baudelaire ante esta situación?». Y al abordar la tarea traductora desde esta perspectiva, entronca con concepciones traductológicas (y lingüísticas) muy alejadas de las recetas funcionalistas que imperan en la mayoría de centros de formación de traductores. Siguiendo la estela de H. Meschonnic (1982 [2009]), Belotto aplica una poética de la traducción que no aspira a encontrar significados previamente encapsulados en los signos lingüísticos; no pretende descifrar un sentido prelingüístico que el poema se limitaría a señalar fuera de sí. No es la lengua la que habla a través de los hablantes ofreciéndoles signos con contenidos preestablecidos, sino que son los hablantes quienes vuelcan su subjetividad en un acto de enunciación cuya significación consiste precisamente en la forma (el ritmo) que adopta el material lingüístico tras ser

se de sus impulsos corporales, de ahí los remordimientos que lo atenazan «igual que a un libertino pobre que besa y come / el pecho torturado de una vieja ramera», nos dice Baudelaire en el primer poema de Las flores del mal. E1 protagonismo de París en Las flores del mal es el mismo que el de Nueva York en este film: más que un mero escenario sombrío, la gran ciudad es un personaje que observa inmisericorde los vanos intentos del ser humano por trascender lo terrenal; vanos porque «el pecado, el error, la idiotez, la avaricia / nuestro espíritu ocupan y el cuerpo nos desgastan» («Al lector», Las flores del mal, trad. de Luis Martínez de Merlo). 
moldeado. Émile Benveniste resulta útil para explicar el proceder de Belotto: «Es entonces la búsqueda y el esclarecimiento de este mecanismo latente lo que sería objeto de la lingüística. El lenguaje admite asimismo ser constituido en estructura de "juego", como un conjunto de "figuras" producidas por las relaciones intrínsecas de elementos constantes» (2004 [1966]: I8). Son estos juegos y estas figuras los que ha pretendido reproducir Belotto en su traducción. Sus análisis rítmicos de los poemas en prosa de Baudelaire buscan ante todo recurrencias sonoras, paralelismos sintácticos, asonancias, similicadencias y otras figuras retóricas a través de las cuales se tejen estas relaciones intrínsecas en el poema; las espacializaciones sintácticas de los textos originales constituyen auténticos caligramas que plasman gráficamente estas figuras mencionadas por Benveniste. Frente a la interpretación («que ejerce sobre el texto una violencia y un arbitrio», en palabras de Italo Calvino, I979 [1980]: 33), Belotto prefiere alinearse con el también poeta y traductor Yves Bonnefoy, para quien traducir ha de consistir ante todo en la «repetición de ese acto de dar forma, de crear, que ha propiciado la obra, que participa de lo mejor, de lo más misterioso de su sentido, y que ninguna interpretación puede restituir ni tal vez siquiera comprender» (Bonnefoy, I994; citado en Belotto, 20I2: XxxIII).

Inspirado, pues, en los principios estéticos que el propio Baudelaire expone en los poemas en prosa, ${ }^{4}$ Belotto busca la poeticidad en un registro coloquial poco frecuentado en las traducciones anteriores. Igual que Baudelaire

4 «Arrière la muse académique! Je n'ai que faire de cette vieille bégueule. J'invoque la muse familière, la citadine, la vivante, pour qu'elle m'aide à chanter les bons chiens, les pauvres chiens, les chiens crottés, ceux-là que chacun écarte, comme pestiférés et pouilleux, excepté le pauvre dont ils sont les associés, et le poëte qui les regarde d'un œil fraternel » («Les Bons Chiens », Petits poèmes en prose). cantaba a los «perros enfangados» y excluía de sus poemas a los «perros presumidos» (a los que confinaba a una «caseta sedosa y acolchada»), Belotto decide también enfangar su traducción. Mientras que otros traductores suelen elevar el registro de Baudelaire (creyendo, quizás, que ciertas palabras no tienen cabida en un poema), nuestro traductor toma la dirección opuesta e incluso rebaja en ocasiones el tono de los textos originales. Así, ante la expresión «fi du chien bellâtre» (que Manuel Neila, por ejemplo, traduce como «fuera el perro presumido»), Belotto propone «Al carajo el perro guaperas». La búsqueda de la oralidad parece responder también a este principio. En el poema «Énivrezvous» (que Belotto traduce significativamente por «Emborrachaos», frente a la equivalencia habitual en muchas otras versiones: «Embriagaos»), Baudelaire se pregunta: «Mais de quoi ?». Mientras que en las demás traducciones se opta mayoritariamente por la literalidad («Pero ¿de qué?»), Belotto prefiere recalcar el modo oral de la lengua traduciendo «¿Que de qué?». Algo similar sucede en el poema «Les Projets». Bastará comparar la traducción de Belotto con la de Manuel Neila para apreciar la búsqueda de la oralidad del primero frente al tono solemne del segundo: «Pues sí que tiene que ser vagabunda mi mente para ir a buscar tan lejos lo que puedo encontrar tan cerca» (Belotto); «Gran vagabundo ha de ser mi pensamiento para ir a buscar tan lejos lo que se encuentra cerca de mí» (Neila).5

No puede pasarse por alto un factor determinante en esta nueva traducción de los Petits poèmes en prose: Jesus Belotto ha ido traduciendo los poemas al mismo tiempo que realizaba una tesis doctoral sobre la recepción en España del poemario francés. No es este el momento

5 «Il faut, - se dit-il, — que ma pensée soit une grande vagabonde pour aller chercher si loin ce qui est si près de moi », escribe Baudelaire. 
de valorar el resultado de la investigación, sino de señalar la incidencia que esta ha tenido en el proceso de traducción, pues la versión que propone Belotto de los poemas en prosa no puede deslindarse de su memoria de doctorado. El traductor conoce bien las distintas retraducciones que se han ido publicando en español desde el siglo pasado, y este profundo conocimiento de quienes lo han precedido en la misma tarea le ha permitido saber dónde se ubica su propuesta. La de Belotto es, por lo tanto, una verdadera retraducción, en la medida en que ha leído las versiones previamente publicadas y estas han influido en su toma de decisiones; en otras palabras: Belotto es consciente de estar traduciendo de nuevo. No todos los traductores de obras clásicas asumen esta estrategia: algunos, de hecho, tienen a gala (y así lo reconocen en sus prólogos) no haber consultado las versiones anteriores a las suyas «para no contaminarse», lo cual nos lleva a plantear alguna matización al uso que habitualmente se hace del concepto de retraducción. Quizás sería necesario distinguir, por un lado, la retraducción entendida como el resultado de que una misma obra se haya traducido en más de una ocasión (independientemente de que los traductores tuviesen o no en cuenta la existencia de otras traducciones previas) y, por otro, la retraducción entendida como un tipo de traducción en el que la conciencia de estar traduciendo de nuevo una misma obra condiciona las estrategias del traductor. Solo en este último caso podemos decir que las nuevas versiones se han enlazado con las anteriores como piezas de un puzle; es decir, condicionadas por la historia del texto original en la cultura receptora.

Esta vinculación entre la labor traductora de Jesús Belotto y su investigación filológica no ha dejado huellas en la superficie textual de su traducción. Estamos ante una traducción poética antes que académica. Las notas son escasas y aparecen al final del libro para no interrumpir la lectura de los poemas. El aparato crítico consta de una introducción que no llega a las veinte páginas (en la que se dan detalles sobre el texto francés y sobre los procedimientos de traducción a los que se ha recurrido); un índice onomástico de los personajes históricos nombrados por Baudelaire en los poemas; una cronología en la que se indica el orden en el que estos se fueron publicando en la prensa de la época; y la traducción de la carta íntegra que Baudelaire mandó a Arsène Houssaye a finales de I86r en la que le anunciaba el envío de los poemas. No habría estado de más que se nos ofreciese una explicación sobre el título de la traducción, que se aparta significativamente no solo del escogido por Banville y Asselineau en la edición póstuma (Petits poèmes en prose), sino también de todos los que Baudelaire sopesó en vida (Le Spleen de Paris, Poèmes nocturnes, La Lueur et la Fumée, Le Promeneur solitair y Le Rôdeur parisien).

El traductor ha puesto especial cuidado en cortar el cordón umbilical entre la traducción y la tesis doctoral, de tal manera que aquella se presenta como una obra independiente de esta. Sin embargo, es imposible no apreciar el parentesco genético de estos dos textos cuando se tienen delante. La semejanza entre las portadas de ambos demuestra que el vínculo es consciente y voluntario. Se trata, sin duda, de un juego visual con el que se pretende difuminar las fronteras entre los géneros textuales (la misma pretensión que empujó a Baudelaire a practicar el poema en prosa en una época en la que poesía se asociaba únicamente con el verso). Poesía, crítica literaria y traducción se presentan, pues, como géneros fusionados: prácticas textuales entroncadas por un mismo impulso creador que adopta formas diferentes según la contingencia del acto de enunciación. También aquí parece inspirarse 
el traductor en Baudelaire, quien escribió en el Salón de 1846 que «el mejor comentario de una pintura bien podría ser un soneto o una elegía», rechazando así todo hiato entre la obra de arte y su posterior comentario. El concepto wagneriano de «obra de arte total» (Gesamtkunstwerk), tan querido por el poeta francés, inspira igualmente al investigador, poeta y traductor Jesús Belotto. Todo en esta traducción parece elegido conscientemente. Hasta el nombre de la editorial («Libros del Innombrable») y de la colección («Golpe de dados», de claras resonancias mallarmeanas) habrían sido muy del gusto de Baudelaire.

\section{REFERENCIAS BIBLIOGRÁFICAS}

Belotto, Jesús (trad.) (2012): Charles Baudelaire. Paris/Spleen. Poemas en prosa. Zaragoza: Libros del Innombrable.

Belotto, Jesús (2012): La traducción y recepción del poema en prosa en España: Le Spleen de Paris de Charles Baudelaire. Tesis doctoral defendida en la Universidad de Alicante y codirigida por Francisco Torres Monreal y Fernando Navarro.

Benveniste, Émile (2004 [1966]): Problemas de Lingǘstica General. Tomo I. (traducción de Juan Almela). México D.F: Siglo Veintiuno Editores.

Bonnefoy, Yves (1994): La Petite Phrase et la longue phrase. París: Le TILV éditeur.

Calvino, Italo (1979 [1980]): Si una noche de invierno un viajero (trad. de Esther Benítez). Barcelona: Bruguera.

Díez-Canedo, Enrique (trad.) (I920): Charles Baudelaire. Pequeños poemas en prosa. Madrid: Imprenta Renovación. Existe edición electrónica en <www.cervantesvirtual.com> [consulta realizada el 28 de enero de 20I3].

Esclasans, Agustí (trad.) (1942): Charles Baudelaire. Pequeños poemas en prosa. Barcelona: María M. Borrat.

Francés, José (trad.) (I9I8): Charles Baudelaire. El Spleen de París. Madrid: Júcar.

Gandía Buleo, Pedro (trad.) (1993). Charles Baude- laire. El Spleen de París. Altea: Aitana.

Guarner, Luis y Vicente Gil-Vilache (trads.) (I973): Charles Baudelaire. Las flores del mal. Los paraísos artificiales. El Spleen de París. Barcelona: Bruguera.

Heras Hernández, Eusebio (I905): Charles Baudelaire. Pequeños poemas en prosa. Barcelona: Biblioteca Castellá.

López Castellón, Enrique (trad.) (2000): Las flores del mal. Pequeños poemas en prosa. Madrid: Edimat.

Meschonnic, Henri (1982 [2009]): Critique du rythme. Anthropologie historique du langage. Lagrasse: Verdier.

Millán Alba, José Antonio (trad.) (1986): Charles Baudelaire. Pequeños poemas en prosa. Los paraísos artificiales. Madrid: Cátedra.

Michelena, Margarita (trad.) (I990): Charles Baudelaire. El Spleen de París. México D. F.: Papeles Privados.

Negrón, Joaquín (trad.) (I997): Charles Baudelaire. Spleen de París. Madrid: Visor.

Neila, Manuel (trad.) (2009): Charles Baudelaire. El Spleen de París: Pequeños poemas en prosa. Sevilla: Espuela de Plata.

Olcina Aya, Emilio (trad.) (I979): Charles Baudelaire. El Spleen de París. Barcelona: Fontanamara.

Oyarzún, Pablo (trad.) (2008): El Spleen de París: Pequeños poemas en prosa. Santiago de Chile: LOM ediciones.

Ruiz Casanova, José Francisco (2000): Aproximación a una historia de la traducción. Madrid: Cátedra.

Ruiz Noguera, Francisco (2007): «La poética propia como impulso para la retraducción», en Juan Jesús Zaro Vera y Francisco Ruiz Noguera (eds.): Retraducir. Una nueva mirada. La retraducción de textos literarios y audiovisuales. Málaga: Miguel Gómez Ediciones, págs. I79-I96.

Torres Monreal, Francisco (trad.) (I999): Charles Baudelaire. El esplín de París: Pequeños poemas en prosa. Madrid: Alianza Editorial.

Uribe, Jaime (trad.) (1985): Charles Baudelaire. El Spleen de París: Pequeños poemas en prosa. Madrid: Club Internacional del Libro.

Vances Cuevas, Pedro (trad.) (c. I9Io): Charles Baudelaire. Pequeños poemas en prosa. Madrid: Jiménez Fraud Editor.

Verjat, Alain (trad.) (1975): Charles Baudelaire. El Spleen de París. Barcelona: Bosch. 